
со средней и тяжелой степенями тяжести акне на фоне
монотерапии изотретиноином (препаратом Сотрет)

(C) Коннов П.Е.', Арсеньева А.А. ${ }^{1 *}$, Токарев Ю.А. ${ }^{2}$

\author{
${ }^{1}$ ФГБОУ ВО «Самарский государственный медицинский университет» Минздрава России \\ 443099, Россия, г. Самара, ул. Чапаевская, д. 89 \\ 2 ФГБОУ ВПО «Самарский государственный экономический университет» \\ 443090, Россия, г. Самара, ул. Советской Армии, д. 141
}

Обоснование. Acne vulgaris являются широко распространенным хроническим заболеванием, не имеющим возрастных, гендерных или расовых ограничений. Оно не несет прямой угрозы жизни пациента, но отражается на его психоэмоциональном статусе, что требует соответствующего медицинского вмешательства.

Цель исследования. Изучить психоэмоциональный статус пациентов в возрасте 22-24 лет с акне средней и тяжелой степеней тяжести и его изменения на фоне монотерапии изотретиноином (препаратом Сотрет). Методы. В открытое нерандомизированное исследование длительностью 12 месяцев были включены 310 студентов ФГБОУ ВО СамГМУ (52\% - здоровые, 33\% - с легкой степенью акне, 13\% - со средней степенью, $2 \%$ - с тяжелой степенью). Всем пациентам в рамках исследования до лечения и через 3, 6, 12 месяцев проводили оценку тяжести течения с помощью дерматологического индекса акне (ДИА); оценку качества жизни с помощью Кардиффоского индекса акне-инвалидизации (шкала CADI); оценку психологического и социального влияния акне с помощью опросника APSEA. Всем больным проводили монотерапию с использованием препарата Сотрет. В качестве описательных статистик указывали медиану и интерквартильное расстояние Ме (Q3-Q1). Для сравнения связанных групп применяли критерий знаковых рангов Вилкоксона. Сравнение проводили с достоверностью 95\%.

Результаты. Приводится анализ оценки психологического и социального статуса пациентов с акне средней и тяжелой степеней тяжести до лечения, через 3, 6, 12 месяцев после начала лечения изотретиноином (Сотрет). Под наблюдением находились 36 человек (20 женщин и 16 мужчин) в возрасте от 22 до 24 лет с длительностью заболевания от 1 года до 10 лет. Результаты психологических тестирований в различные промежутки времени дали сопоставимые данные: у всех пациентов был выраженный стойкий уровень социальной дезадаптации. Важным показателем эффективности терапии акне изотретиноином является частота случаев фрормирования стойкого клинического эффректа от лечения, что наглядно выражается в восстановлении психоэмоционального фона пациентов, улучшении качества жизни пациентов.

Заключение. Важным показателем эффективности терапии акне препаратом Сотрет является частота случаев формирования стойкого клинического эфффекта от лечения, что наглядно выражается в восстановлении психоэмоционального фона пациентов, улучшении качества жизни пациентов. Лечение позволило изменить психоэмоциональный фон наших пациентов в лучшую сторону, что повысило их мотивацию к учебе, общению, стремление к саморазвитию.

Ключевые слова: акне, изотретиноин, препарат Сотрет, дерматологический индекс акне (ДИА), Кардиффский индекс акне-инвалидизации (шкала CADI), опросник APSEA.

Конфрликт интересов: авторы заявляют об отсутствии потенциального конфллита интересов, требующего раскрытия в данной статье.

Источник фринансирования: исследование и публикации статьи осуществлены на личные средства авторского коллектива.

Для цитирования: Коннов П.Е., Арсеньева А.А., Токарев Ю.А. Изучение психоэмоционального статуса пациентов со средней и тяжелой степенями тяжести акне на фоне монотерапии изотретиноином (препаратом Сотрет). Вестник дерматологии и венерологии. 2020;96(6):48-55. doi: https://doi.org/10.25208/vdv1189 


\title{
Study of the psychoemotional status of patients with medium and severe acne severity on the background of isotretinoin monotherapy (Sotret)

\author{
(C) Pavel E. Konnov ${ }^{1}$, Antonina A. Arsenieva ${ }^{1 *}$, Yuri A. Tokarev²
}

\author{
${ }^{1}$ Federal State Budgetary Educational Institution of Higher Education "Samara State Medical University" of the Ministry \\ of Healthcare of the Russian Federation \\ Chapaevskaya str., 89, Samara, 443099, Russia \\ 2 Samara State University of Economics \\ Soviet Army str., 141, Samara, 443090, Russia
}

Rationale. Acne vulgaris is a widespread chronic disease with no age, gender, or race restrictions. It does not pose a direct threat to the patient's life, but is reflected in his psycho-emotional status, which requires appropriate medical intervention.

Purpose of the study. To study the psychoemotional status of patients aged 22-24 years with moderate and severe acne and its changes during monotherapy with isotretinoin (Sotret).

Methods. In an open, non-randomized study lasting 12 months, 310 students of the Samara State Medical University were included (52\% - healthy, 33\% — with mild acne, $13 \%$ - with a moderate degree, $2 \%$ — with a severe degree). All patients in the study before treatment and after 3, 6, 12 months were assessed the severity of the course using the dermatological index of acne (DIA); quality of life assessment - using the Cardiff Acne Disability Index (CADI scale); assessment of the psychological and social impact of acne using the APSEA questionnaire. All patients received monotherapy using the drug Erase. The median and interquartile distance Me (Q3-Q1) were indicated as descriptive statistics. The Wilcoxon signed rank test was used to compare related groups. The comparison was carried out with 95\% confidence.

Results. An analysis of the assessment of the psychological and social status of patients with moderate and severe acne before treatment, 3, 6, 12 months after the start of treatment with isotretinoin (Erase) is presented. The study included 36 people (20 women and 16 men) aged 22 to 24 years with a disease duration from 1 to 10 years. The results of psychological testing at various intervals gave comparable data: all patients had a pronounced persistent level of social maladjustment. An important indicator of the effectiveness of acne therapy with isotretinoin is the frequency of cases of the formation of a persistent clinical effect from treatment, which is clearly expressed in the restoration of the psycho-emotional background of patients, improving the quality of life of patients.

Conclusion. An important indicator of the effectiveness of acne therapy with Erase is the frequency of cases of the formation of a stable clinical effect of treatment, which is clearly expressed in the restoration of the psychoemotional background of patients, improving the quality of life of patients. The treatment allowed us to change the psychoemotional background of our patients for the better, which increased their motivation to study, communication, and the desire for self-development.

Keywords: acne, isotretinoin, Sotret, Acne Dermatological Index (DIA), Cardiff Acne Disability Index (CADI scale), APSEA questionnaire.

Conflict of interest: the authors state that there is no potential conflict of interest requiring disclosure in the article.

Source of funding: research and publications article were carried out on personal funds.

For citation: Konnov PE, Arsenieva AA, Tokarev YA. Study of the psychoemotional status of patients with medium and severe acne severity on the background of isotretinoin monotherapy (Sotret). Vestnik Dermatologii i Venerologii. 2020;96(6):48-55. doi: https://doi.org/10.25208/vdv1189 


\section{Обоснование}

Акне (acne vulgaris) - воспалительное заболевание кожи, имеющее хроническое течение, проявляющееся комедонами (открытыми или закрытыми) и поражениями воспалительного характера в виде папулезных, пустулезных, узловатых эффрлоресценций [1]. Акне - это заболевание, которое лидирует в западных странах по частоте обращений к специалистам (врачам-дерматовенерологам) [2, 3]. Во всем мире с проблемой акне в различном возрасте встречаются 80-95\% населения. На период 12-25 лет приходится пик заболеваемости, при этом акне наблюдаются и в более позднем возрасте. После окончания полового созревания высыпания могут впервые возникнуть в $41 \%$ случаев. Патогенез акне является мультифакториальным: увеличение продукции кожного сала, избыточный фролликулярный гиперкератоз, размножение $P$. acnes и воспаление [4]. В последние годы внесены изменения в таксономию бактерий: в современной классификации изменено название Propionibacterium acnes на Cutibacterium acnes. C. acnes относится к роду Cutibacterium, который входит в семейство пропионовокислых бактерий Propionibacteriaceae [5]. При acne vulgaris, по сравнению с многими другими дерматозами, чаще всего поражения локализуются на коже лица, что негативно отражается на психоэмоциональном фоне пациентов $[6,7]$. Высокая распространенность, длительное течение, неадекватная терапия приводят к резкому снижению качества жизни, социальной дезадаптации пациентов, появлению психосоматических расстройств, что делает проблему актуальной и социально значимой. Выбор метода лечения напрямую зависит от клинической картины и степени тяжести акне: при легком течении применяются топические лекарственные средства, для средних и тяжелых форм назначается системная терапия - антибиотики, гормональные лекарственные средства (например, КОК) и синтетические ретиноиды. Согласно европейским клиническим рекомендациям (European Dermatology Forum, 2016), изотретиноин (ИТ) является одним из наиболее эффективных средств лечения тяжелых форм акне [7, 8]. Индивидуальное восприятие пациентом косметического дефекта не взаимосвязано с объективной тяжестью течения заболевания, а это приводит к серьезным социальным и психологическим проблемам [9]. Лечение акне любой степени тяжести является современной, актуальной проблемой в дерматологии как для пациента, так и для его врача. ИТ одобрен FDA для системной терапии больных акне с 1982 г. На текущий момент ИТ является одним из самых эфффективных средств в терапии заболевания, при этом отмечаются стойкая длительная ремиссия или полное выздоровление [10]. Применение системного ИТ приводит к улучшению психоэмоционального статуса, что подтверждается снижением индексов CADI, APSEA в результате лечения, причем динамика индексов связывается с положительной динамикой кожного процесса, что отражено в индексах ДИА [11].

Цель исследования: изучить психоэмоциональный статус пациентов в возрасте 22-24 лет с акне средней и тяжелой степеней тяжести и его изменения на фроне монотерапии изотретиноином (препаратом Сотрет).

\section{Методы}

Дизайн исследования

Проведено открытое нерандомизированное исследование.

С периодичностью в 3 месяца всем пациентам проводилось: 1) определение тяжести течения акне (по индексу ДИА); 2) оценка качества жизни (по шкале $\mathrm{CADI}$; 3) оценка психологического и социального влияния угревой болезни (по опроснику APSEA). Кроме того, пациентам проводили монотерапию с использованием препарата Сотрет. По истечении 12 месяцев были сделаны выводы о статистической значимости изменений по каждому параметру (ДИА, CADI, APSEA) и об изменении психоэмоционального статуса пациентов.

Продолжительность исследования

Исследование проводилось в течение 12 месяцев.

Описание медицинского вмешательства

Всем пациентами в рамках исследования до лечения и через 3, 6, 12 месяцев проводили:

1. Определение тяжести течения акне врачом-дерматовенерологом при первичном и последующих осмотрах с помощью оценки дерматологического индекса акне (ДИА), который учитывает количество высыпаний (комедонов, папул, пустул и узлов). Для объективизации оценки клиники акне кафедра кожных и венерических болезней ММА им. И. М. Сеченова разработала опросник «Дерматологический индекс акне» (ДИА), который позволяет стандартизировать оценку степени тяжести акне. ДИА представляет собой сумму баллов, которая количественно выражает каждый из основных симптомов акне (комедоны, папулы, пустулы, узлы). Минимальное значение ДИА обозначает отсутствие симптомов заболевания, равно 0, а максимальное 15 , что соотносится с тяжелой формой акне. Выделяются интервалы:

легкая форма акне - ДИА от 1 до 5 баллов;

средняя форма акне - ДИА от 6 до 10 баллов;

тяжелая форма акне - ДИА от 11 до 15 баллов.

Важно: наличие 1-2 узловатых эфффлоресценций говорит о тяжелой форме течения заболевания.

2. Оценку качества жизни (Кардиффрский индекс акне-инвалидизации). Шкала CADI - это краткий опросник из 5 вопросов, предназначенный для применения у больных акне молодого возраста, который не требует каких-либо пояснений для пациента перед тестированием.

3. Оценку психологического и социального влияния угревой болезни с помощью опросника APSEA (Assessment of Psychological and Social Effect of Acne), который состоит из 15 вопросов. Их них 6 первых вопросов имеют по 4 варианта ответов, из которых нужно выбрать только 1. За ответ начисляется 0, 3, 6 или 9 баллов. Остальные 9 вопросов оцениваются по визуальной аналоговой шкале от 0 до 10 баллов. Минимальное количество баллов за тест 0, максимальное число баллов за тест 144, при этом чем больше сумма баллов, тем сильнее акне снижает качество жизни пациента.

Все исследуемые получали монотерапию препаратом Сотрет. Доза изотретиноина: 0,5-0,75 мг/кг массы тела в сутки. Продолжительность курса терапии определялась сроками достижения кумулятивной дозы препарата 120-150 мг/кг и значительным клиническим эфрфектом от приема препарата Сотрет (в среднем 
составила 30,21 $\pm 2,11$ недели). До лечения, а также во время терапии 1 раз в месяц проводили определение уровней АЛАТ, АСАТ, холестерина, триглицеридов, щелочной фоссратазы стандартными методами, а также тест на беременность для женщин.

\section{Статистический анализ}

Все показатели, оцениваемые в исследовании, были проверены на соответствие нормальному закону распределения с помощью критерия Шапиро - Уилка. Для всех показателей распределение оказалось значимо отличным от нормального, поэтому для описания данных применяли медиану и интерквартильное расстояние Ме (Q3-Q1), а для сравнения связанных групп - непараметрический критерий знаковых рангов Вилкоксона. Сравнение проводили с достоверностью 95\%.

Анализ результатов был осуществлен с помощью пакета прикладных вычислительных программ Statistica 12.0.

\section{Результаты}

\section{Объекты (участники) исследования}

Нами было осмотрено 310 студентов 4, 5, 6-го курсов ФГБОУ ВО СамГМУ Минздрава России. Из 310 обследуемых - 160 (52\%) человек здоровы; 102 (33\%) человека с легкой степенью тяжести; 40 (13\%) человек со средней степенью тяжести, из них 28 (9\%) включены в исследование в соответствии с критериями включения; 8 (2\%) с тяжелой степенью акне. Критериями включения в исследование были: возраст (мужчины и женщины) - от 22 до 24 лет (средний возраст больных $20,3 \pm 3,16$ года); степень тяжести акне - средняя и тяжелая степени тяжести; длительность заболевания от 1 года до 10 лет; неэффективность ранее получаемой терапии; склонность к рубцеванию, способность выполнять требования исследования и предоставление письменного информированного согласия пациента. Критерии исключения: комедональная форма акне, нарушение функции печени, положительный тест на беременность, а также женщины, планирующие беременность в период лечения.
Под наблюдением находились 36 человек: 20 женщин (средний возраст 21,4 \pm 4,12 года) и 16 мужчин (средний возраст 23,01 $\pm 3,11$ года).

Основные результаты исследования

1. При определении тяжести течения акне при первичном и последующих осмотрах (через 3, 6, 12 месяцев после начала лечения) с помощью ДИА у всех исследуемых пациентов был получен следующий результат: до начала лечения значение ДИА 11,3 2 2,10 балла; через 3 месяца после начала лечения 9,8 $\pm 1,05$ балла (клинически была отмечена положительная динамика: сократилось число элементов сыпи, узлы уменьшились, посветлели); через 6 месяцев после начала лечения 4,47 \pm 1,90 балла (узловато-кистозных элементов нет, папулезно-пустулезные высыпания регрессируют), через 12 месяцев от начала лечения 2,02 \pm 1,86 балла (кожа очистилась, отмечается рубцовая атрофия) (рис. 1).

Выявленные различия статистически достоверны ( $p<0,05$ при каждом сравнении).

2. При исследовании качества жизни с помощью Кардиффского индекса акне-инвалидизации CADI у всех пациентов при первичном и последующих осмотрах (через 3, 6, 12 месяцев после начала лечения) установлено до начала лечения значение индекса - 85,4\% (12,81 \pm 1,84 балла), что соответствует очень высокому уровню тревожности; через 3 месяца после начала лечения $-69,3 \%$ (10,4 $\pm 2,54$ балла), что также соответствует высокому уровню тревожности; через 6 месяцев после начала лечения - 42,1\% (6,3 \pm 1,24 балла) - уровень тревожности носит умеренный характер; через 1 год после начала лечения - 15,7\% (2,4 + 1,07 балла), что соответствует низкому уровню тревожности (рис. 2).

3. При оценке психологического и социального влияния акне с помощью опросника APSEA у всех исследуемых пациентов при первичном и последующих осмотрах (через 3, 6, 12 месяцев после начала лечения) следующие показатели: до начала лечения $-121 \pm 3,15$ балла, что соответствует значительному психологическому и социальному влиянию акне; через 3 месяца после начала лечения - $104 \pm 1,05$ балла, что соответствует

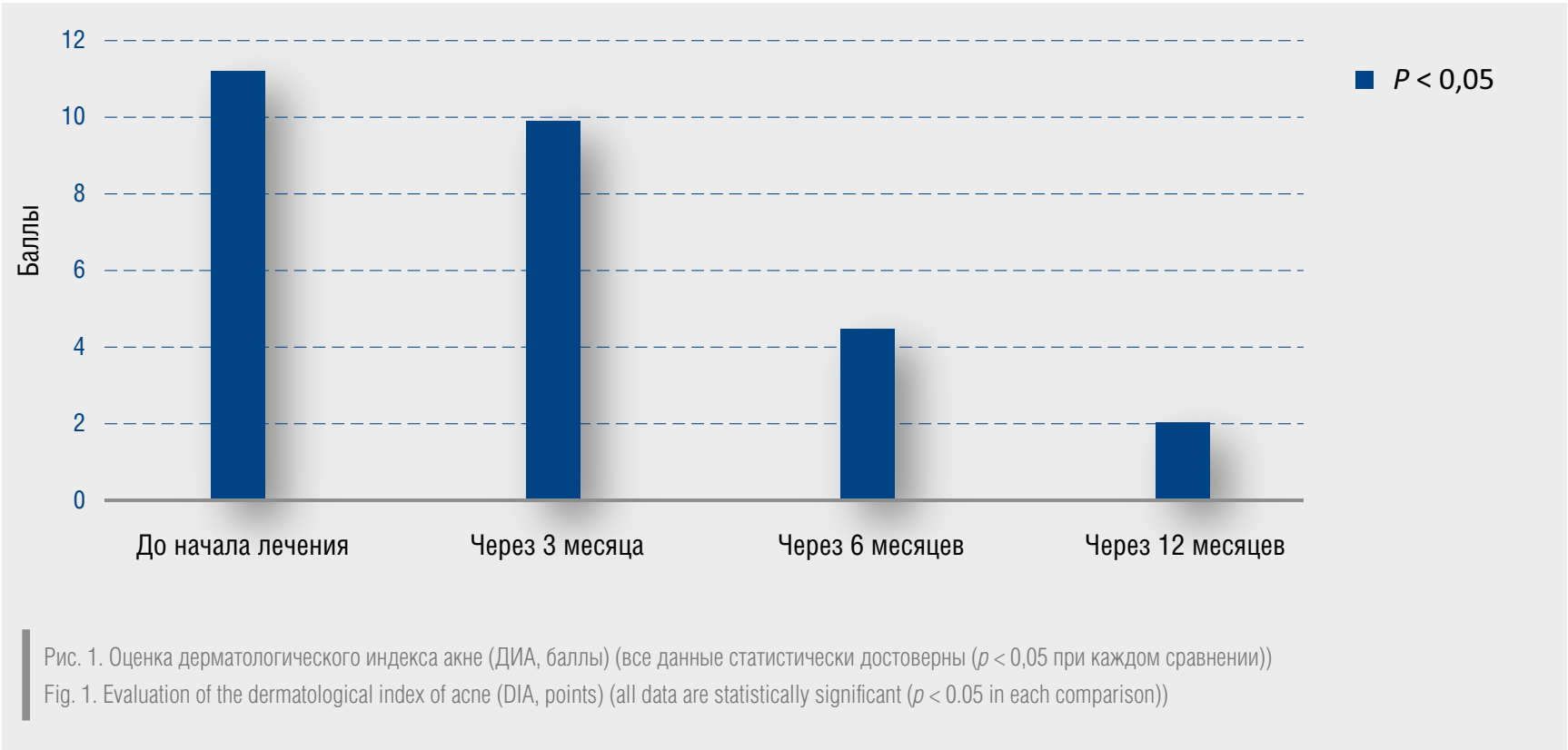


значительному психологическому и социальному влиянию заболевания, наметилась положительная динамика; через 6 месяцев после начала лечения - 39,1 $\pm 2,07$ балла, что соответствует умеренному психологическому влиянию акне; через 1 год после начала лечения $13,2 \pm 2,08$ балла, что соответствует незначительному психологическому и социальному влиянию акне на пациентов (рис. 3).

Типичным примером является приводимый клинический случай.

Пациент В., 24 года, пол: мужской, цвет кожи: II фрототип, светлая. Анамнез заболевания: болен в течение
5 лет. Наследственный анамнез: отец страдал акне с 14 лет. Дебют заболевания в возрасте 19 лет. Другие существенные сведения по анамнезу заболевания: нет. Предшествовавшее лечение и его эффрективность: топические препараты (без эффректа).

Визуально Status localis представлен на рис. 4.

Поражение кожи носит островоспалительный характер. На коже лица (височных областях, областях лба и щек, подбородка) локализуется обильная сыпь, состоящая из не менее 25 папулезных и пустулезных элементов на гиперемированном основании, в том числе 5 вскрывшихся и 4 регрессирующих элемента. В основа-

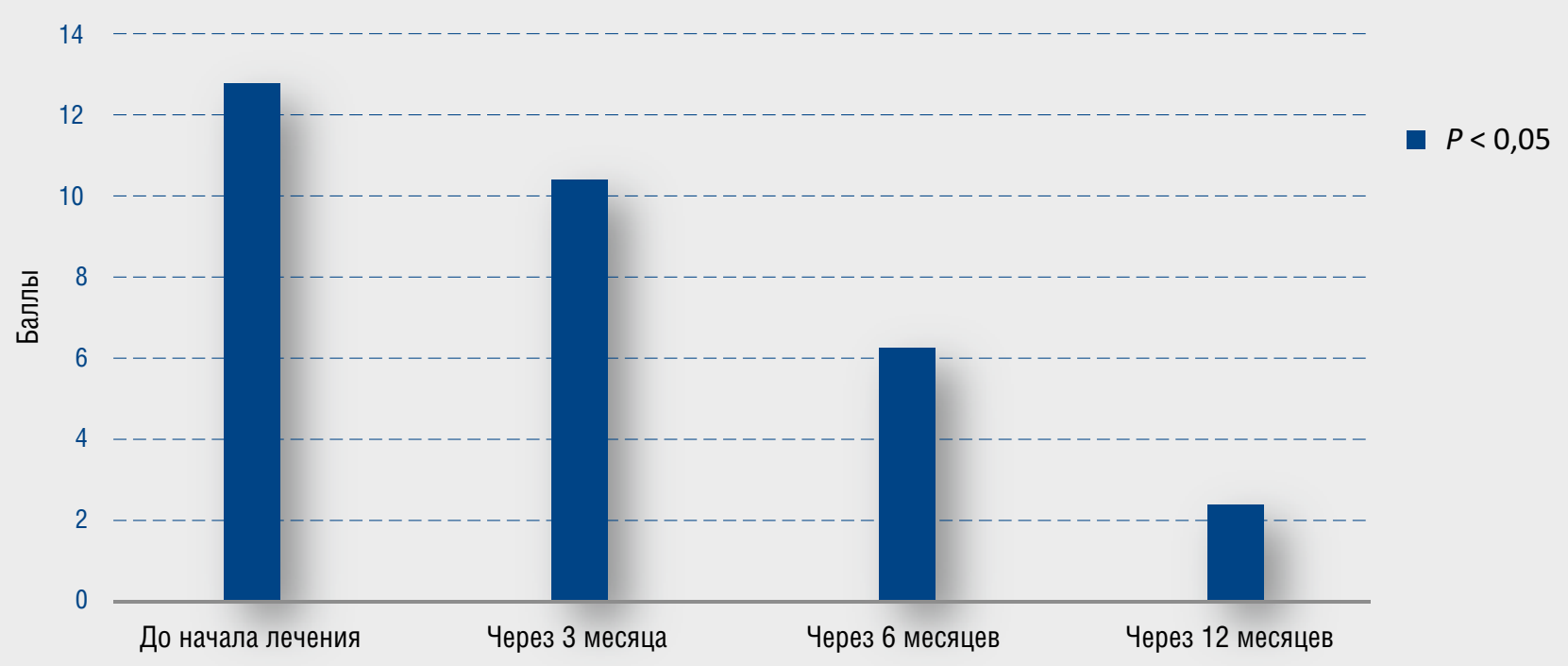
Pис. 2. Кардифффский индекс акне-инвалидизации (шкала CADI, баллы) (все данные статистически достоверны ( $p<0,05$ при каждом сравнении))
Fig. 2. Cardiff Acne Disability Index (CADI scale, points) (all data are statistically significant ( $p<0.05$ in each comparison))

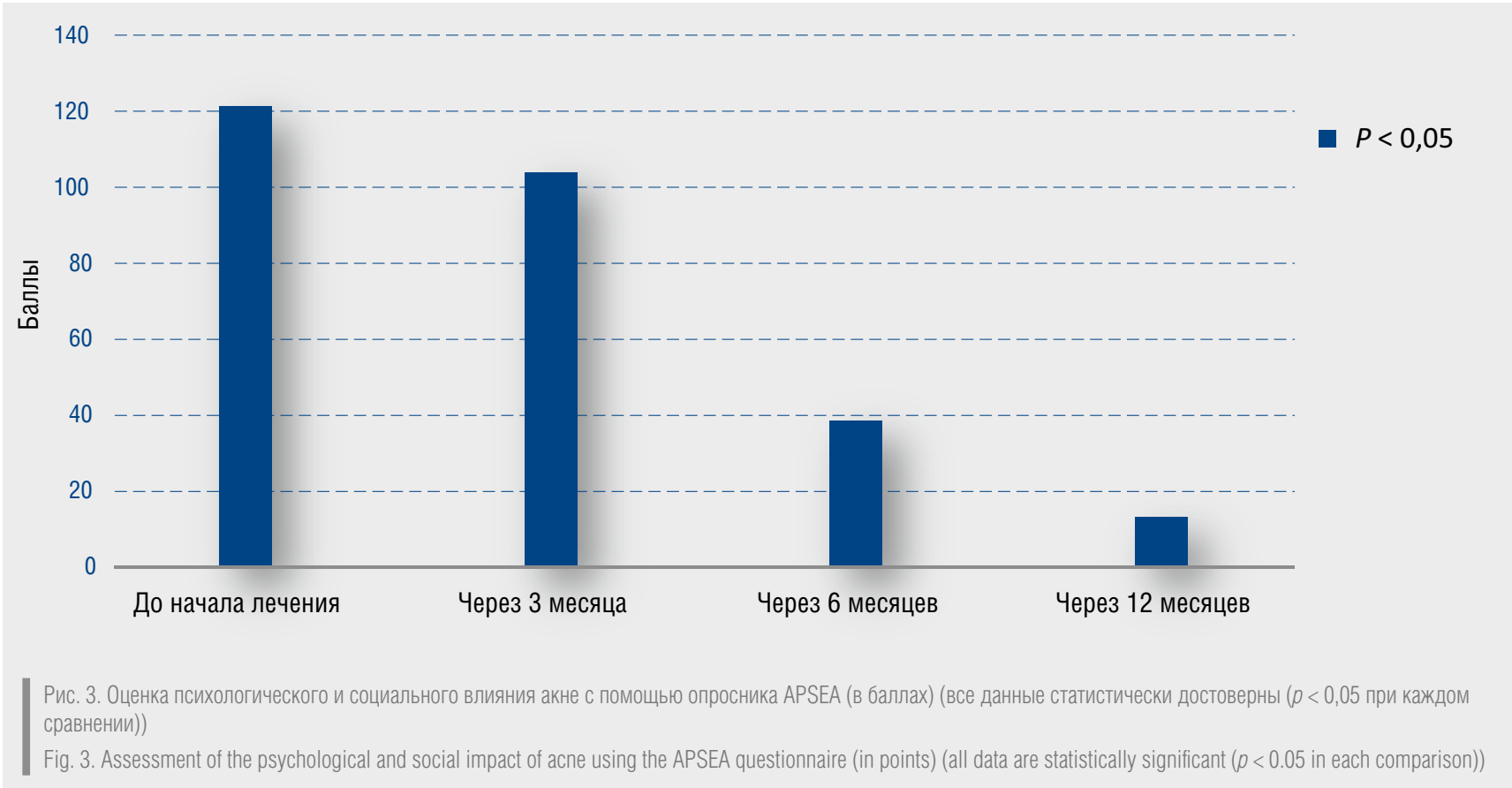




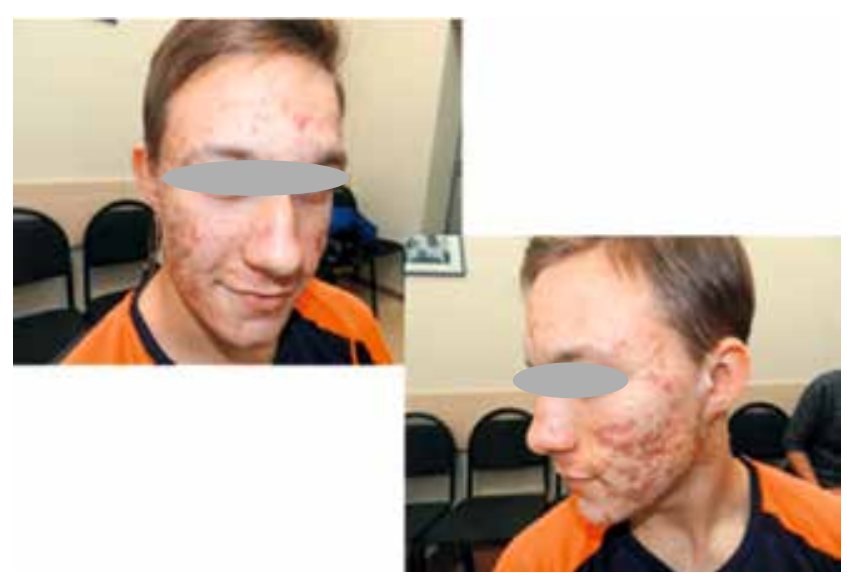

Рис. 4. Пациент В., 24 года. До начала лечения

Fig. 4. Patient V., 24 years old. Before starting treatment нии элементов воспалительная инфильтрация. На коже щек и подбородка имеются узловатые образования, темно-розового цвета, 0,5-0,7 см, плотные и болезненные при пальпации.

Эритема занимает всю зону поражения, умеренного характера, с неправильными очертаниями, резко отграничена от здоровой кожи, поверхность ее гладкая, плотноватой консистенции.

Множественные гипертрофические и атрофические рубцы.

В области лба, щек наблюдается блеск как результат гиперпродукции кожного сала.

Клинический диагноз: акне абсцедирующие. Осложнения: не выявлено.

Ход лечения, методы и результаты

Вес пациента 64 кг. Была назначена монотерапия изотретиноином (Сотрет). Начальная суточная доза: 0,5 мг/кг массы тела в сутки. Длительность терапии: 9 месяцев. Курсовая доза: 126 мг/кг. Дополнительно назначалась адъювантная терапия: эмоленты, фротопротекторы.

Визуально результаты лечения представлены на рис. 5.

Рассмотрим индивидуальную динамику степени тяжести течения акне, оценку качества жизни; оценку психологического и социального влияния угревой болезни.

1. Оценка ДИА.

Результат: до лечения получен результат 12 баллов - соответствует тяжелой степени акне; через 3 месяца после начала лечения 11 баллов, наметилась положительная динамика (узлы уменьшились в размере, стали светло-розовыми с тенденцией к рассасыванию, незначительно сократилось число элементов сыпи); через 6 месяцев после начала лечения результат 6 баллов, значительный регресс папулезных и пустулезных высыпаний, узлы рассосались; через 12 месяцев после начала лечения 4 балла, кожа лица очистилась, видны единичные комедоны, рубцовая атрофия кожи (рис. 6).

2. Шкала CADI. Кардиффрский индекс акне-инвалидизации (социальной дезадаптации).
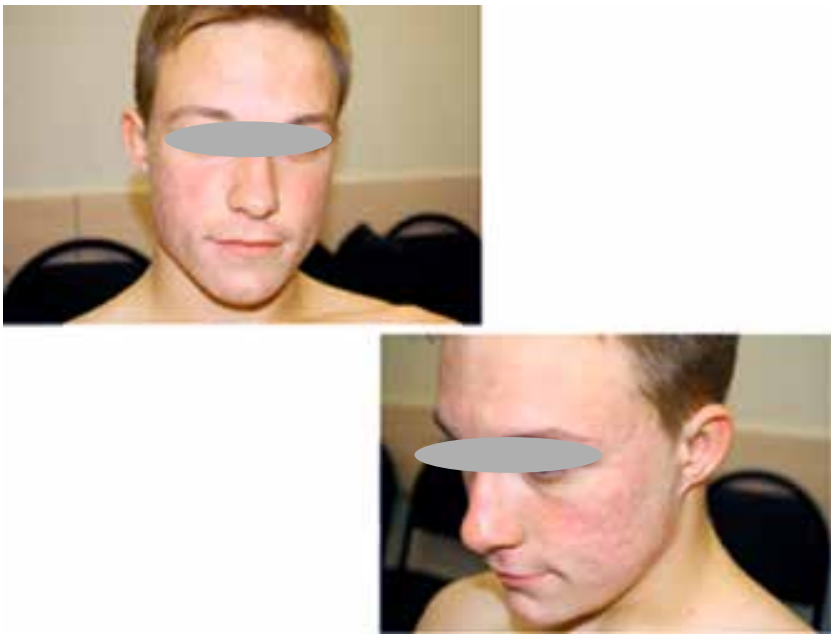

Рис. 5. Пациент В., 24 года. Через 12 месяцев после начала лечения Fig. 5. Patient $\mathrm{V}$., 24 years old. 12 months after starting treatment

Результат: результат до начала лечения $84 \%$ (13 баллов) - соответствует очень высокому уровню тревожности; через 3 месяца после начала лечения $66 \%$ (10 баллов) - соответствует высокому уровню тревожности; через 6 месяцев после начала лечения 37\% (6 баллов) - уровень тревожности носит умеренный характер; через 1 год после начала лечения 8\% (1 балл) - низкий уровень тревожности (рис. 7).

3. Оценка психологического и социального влияния угревой болезни с помощью опросника APSEA.

Результат: до начала лечения 117 баллов - соответствует значительному психологическому и социальному влиянию заболевания акне; через 3 месяца после начала лечения 106 баллов - соответствует значительному психологическому и социальному влиянию данного заболевания, наметилась положительная динамика; через 6 месяцев после начала лечения 38 баллов - соответствует умеренному психологическому влиянию акне; через 1 год от начала лечения 19 баллов - соответствует незначительному психологическому и социальному влиянию заболевания (рис. 8). 


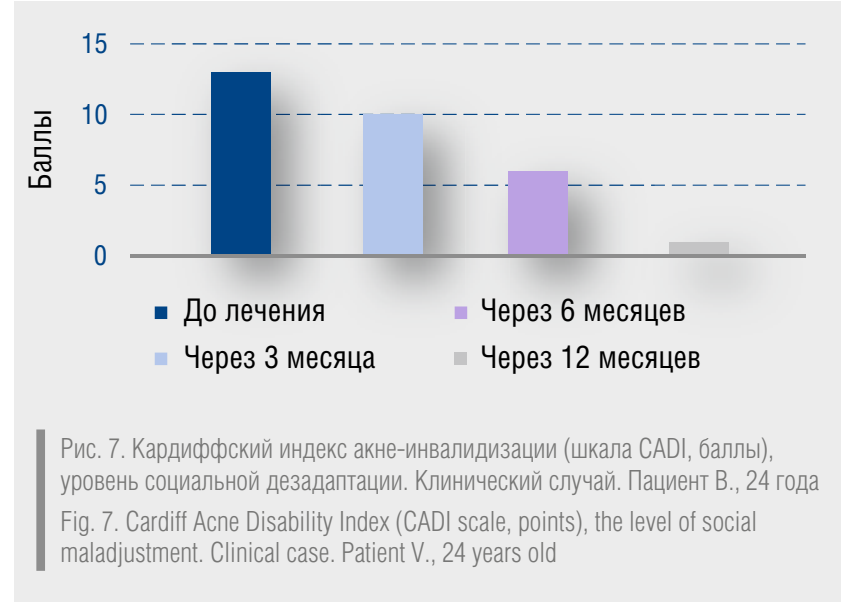

\section{Обсуждение}

Во время проведения курса лечения ни у одного пациента серьезных побочных эффректов зафиксировано не было. Особенно часто встречались: хейлит (100\%) и дерматит лица (46\%), сухость слизистой носа (30\%), кожи (22\%). Чуть реже: кожный зуд (12\%) и сухость конъюнктивы (6\%), кровоточивость слизистой носа (3\%), миалгии (2\%). В то же время сухость кожи, хейлит и дерматит лица благополучно устранялись увлажняющими средствами. Для профилактики сухости конъюнктивы пациентам с акне назначали препараты гипромеллозы. Причиной миалгии, отмеченной лишь у $2 \%$ пациентов, явились занятия профессиональными видами спорта. После коррекции дозы препарата и уменьшения фризической нагрузки данные симптомы исчезли. Для уменьшения рисков возникновения побочных эффректов со стороны печени и поджелудочной железы перед началом лечения и в процессе терапии пациентам проводился биохимический анализ крови с обязательным определением трансаминаз и липидов. В ходе нашего исследования клинически значимых отклонений от нормы этих показателей диагностировано не было: несущественное повышение уровня холестерина зарегистрировано у 4\%, активности трансаминаз у 1,5\%. Данные показания полностью корректировались диетой с низким содержанием жиров и назначением гепатопротекторов.

Сотрет является препаратом, который отличается выраженной эффеективностью и противорецидивной активностью в терапии акне средней и тяжелой степени тяжести. Все побочные действия терапии легко предсказуемы и поддаются коррекции, поэтому, несмотря на большое количество заявленных возможных нежелательных эффректов, стандартный курс терапии акне препаратом Сотрет хорошо переносится и относительно безопасен. Некоторые описываемые неудачи в лечении следует увязывать с неверной оценкой или недостаточной диагностикой основного и сопутствующих

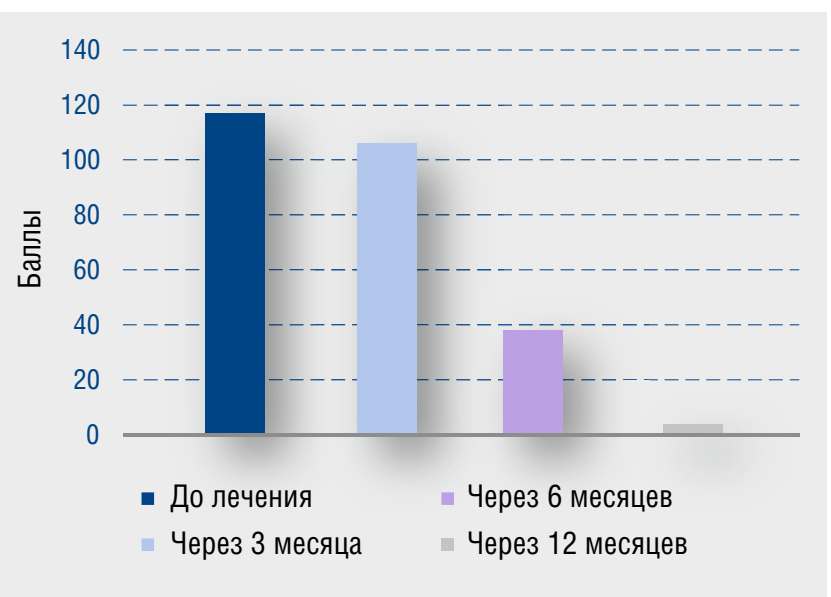

Рис. 8. Оценка психологического и социального влияния акне с помощью опросника APSEA (в баллах). Клинический случай. Пациент В., 24 года Fig. 8. Assessment of the psychological and social impact of acne using the APSEA questionnaire (in points). Clinical case. Patient V., 24 years old

заболеваний пациента, взятием на лечение без учета предварительного обследования и противопоказаний, а также с отсутствием мер профилактики возможных осложнений (адекватной фотопротекции, применения эмолентов) [4-6].

\section{Заключение}

Результаты психологических тестирований в различные промежутки времени дали сопоставимые данные: у всех пациентов был выраженный стойкий уровень социальной дезадаптации, по данным психологических тестирований, который снижался в ходе лечения изотретиноином (Сотрет). Важным показателем эффрективности терапии акне препаратом Сотрет является частота случаев формирования стойкого клинического эффректа лечения, что наглядно выражается в восстановлении психоэмоционального фона пациентов, улучшении качества жизни пациентов.

Применение Сотрета в терапии средней и тяжелой форм акне является эффрективным и безопасным и соответствует требованиям современных принципов лечения. Сотрет показал высокую терапевтическую эффрективность, низкий риск серьезных нежелательных эффректов, что говорит о целесообразности его активного назначения с целью повышения качества оказания квалифицированной специализированной медицинской помощи пациентам с акне. Высокая эффективность, безопасность и оптимальный фармакоэкономический индекс повышают комплаентность терапии. Лечение позволило изменить психоэмоциональный фон наших пациентов в лучшую сторону, что повысило их интерес к учебе, желание к общению, стремление к саморазвитию. 


\section{Литература/References}

1. Самцов А.В., Аравийская Е.Р. и др. Федеральные клинические рекомендации по ведению больных акне. М., РОДВК, 2015. 23 с. [Samtsov AV, Araviyskaya ER, et al. Federal clinical guidelines for the management of acne patients. M., RODVK, 2015. 23 p. (In Russ.)]

2. Gollnick HP, Zouboulis CC. Not all acne is acne vulgaris. Dtsch Arztebl Int. 2014 Apr 25; 111(17):301-12.

doi: 10.3238 / arztebl.2014.0301

3. Pawin $\mathrm{H}$, Chivot M, Beylot $\mathrm{C}$, et al. Living with acne. A study of adolescents' personal experiences. Dermatology. 2007; 215(4):308-14. doi: 10.1159/ 00010762

4. Plewig G, Kligman AM. Acne and rosacea. Springer Science \& Business Media, 2012. P. 270. doi: 10.1007/978-3-642-97234-8

5. Dréno B, Pécastaings $S$, Corvec $S$, et al. Cutibacterium acnes (Propionibacterium acnes) and acne vulgaris: a brief look at the latest updates. J Eur Acad Dermatol Venereol. 2018 Jun; 32 Suppl 2:5-14. doi: 10.1111 / jdv.15043

6. Rocha MA, Costa CS, Bagatin E. Acne vulgaris: an inflammatory disease even before the onset of clinical lesions. Inflamm Allergy Drug Targets. 2014; 13(3):162-7. doi:10.2174/1871528113666140606110024

7. Федеральные клинические рекомендации. Дерматовенерология 2015: Болезни кожи. Инфекции, передаваемые половым путем. 5-е изд., перераб. и доп. М.: Деловой экспресс, 2016;768 с.
[Federal clinical guidelines. Dermatology 2015: diseases of the skin. Sexually transmitted infections. 5th ed., reprint. Moscow: Delovoy express, 2016;768 p. (In Russ.)]

8. Nast A, Dréno B, Bettoli V, et al. European evidence-based (S3) guideline for the treatment of acne - update 2016 — short version. J Eur Acad Dermatol Venereol. 2016 Aug; 30(8):1261-8. doi: 10.1111 / jdv.13776

9. Franzke N, Zimmer L, Schäfer I, et al. Quality of medical care of patients with acne vulgaris in Germany - nationwide survey of pharmacy clients. J Dtsch Dermatol Ges. 2009 Dec; 7(12):1060-3.

doi: 10.1111 / j.1610-0387.2009.07155

10. Стаценко А.В., Белоусова И.Э., Хайрутдинов В.Р. и др. Клинический опыт применения изотретиноина в терапии тяжелых форм акне. Эфффективная фармакотерапия. 2014;1(4):4-6. [Statsenko AV, Belousova IE, Khairutdinov VR, et al. Clinical experience of isotretinoin use in the treatment of severe acne. Effective pharmacotherapy. 2014;1 (4):4-6 (In Russ.)]

11. Арипова М. Л., Хардикова С.А. Психоэмоциональное состояние пациентов с тяжелой степенью акне на фоне терапии изотретиноином. Вестник дерматологии и венерологии. 2015;91(5):122-127. [Aripova ML, Hardikova SA. Psychoemotional state of patients with severe acne on the background of isotretinoin therapy. Vestnik of Dermatology and Venereology. 2015; 91(5):122-127 (In Russ.)]

\section{Информация об авторах}

*Антонина Александровна Арсеньева - к.м.Н., доцент; адрес: Россия, 443099, г. Самара, ул. Чапаевская, д. 89; ORCID iD: https://orcid.org/0000-0002-7933-3515; eLibrary SPIN: 777266; e-mail: a.arsenieva2014@yandex.ru

Павел Евгеньевич Коннов — K.м.H., доцент; ORCID iD: https://orcid.org/0000-0002-6505-7953; eLibrary SPIN:349555; e-mail: konnoff@yandex.ru

Юрий Алексеевич Токарев — к.э.н., доцент; ORCID iD: https://orcid.org/0000-0001-9842-8504; eLibrary SPIN: 8507-2981; e-mail: tokarev_ya@mail.ru

\footnotetext{
Information about the authors

*Antonina A. Arsenieva - MD, Cand. Sci. (Med.), assistant professor; address: 89 Chapaevskaya street, 443099, Samara, Russia; ORCID iD: https://orcid.org/0000-0002-7933-3515; eLibrary SPIN: 777266; e-mail: a.arsenieva2014@yandex.ru

Pavel E. Konnov - MD, Cand. Sci. (Med), assistant professor; ORCID iD: https://orcid.org/0000-0002-6505-7953; eLibrary SPIN:349555; e-mail: konnoff@yandex.ru

Yuri A. Tokarev — Cand. Sci. (Econ.), assistant professor; ORCID iD: https://orcid.org/0000-0001-9842-8504; eLibrary SPIN: 8507-2981; e-mail: tokarev_ya@mail.ru
}

Статья поступила в редакцию: 24.11.2020

Принята к публикации: 18.12 .2020

Дата публикации: 30.12.2020
Submitted: 24.11 .2020

Accepted: 18.12 .2020

Published: 30.12 .2020 